\title{
The future's bright
}

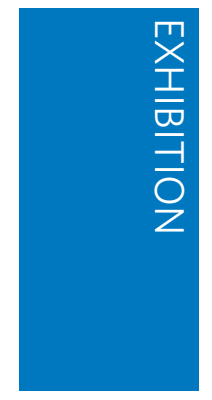

What happens when you bring artists, designers and computer animators together with engineers, programmers and mathematicians? According to teamLab, who have been doing just that since 2001, you get a group of ultratechnologists who can move beyond the boundaries of science, technology and art. The group's interactive installations have featured in exhibitions all over the world and, last year, they added a permanent exhibition to the ArtScience Museum in Singapore to their list. Known as Future World, the installation is billed as Singapore's largest permanent digital art gallery.

Perhaps the best way to describe Future World is as a digital playground, rather than an educational experience. It consists of 16 installations that use cutting-edge technology to enable visitors to explore and interact with themes from nature and society. The exhibit starts with a dark corridor that leads to a room teeming with life and colour: butterflies flutter around the room, gathering on blossoming flowers. The environment is rendered in real time by a computer programme, continuously changing so that one hour represents a seasonal year of flowers. The environment is interactive, too, with flowers shedding their petals as people move closer to them, highlighting the effect we have on our environment.

Beyond the flowers and butterflies is a film showing waves across a 20 -metre screen. Continuing the theme of humannature interactions, the film is there to draw attention to the World Wildlife Fund for Nature's 2009 prediction that the global sea levels will rise $120 \mathrm{~cm}$ by the end of this century. With 100 years of sea condensed into ten minutes, the viewers watch as the waves crash against small islands, eventually covering all the land before eerily engulfing the whole screen.

After this thought-provoking entrance, the exhibition really comes to life - quite literally. A world in which your drawings

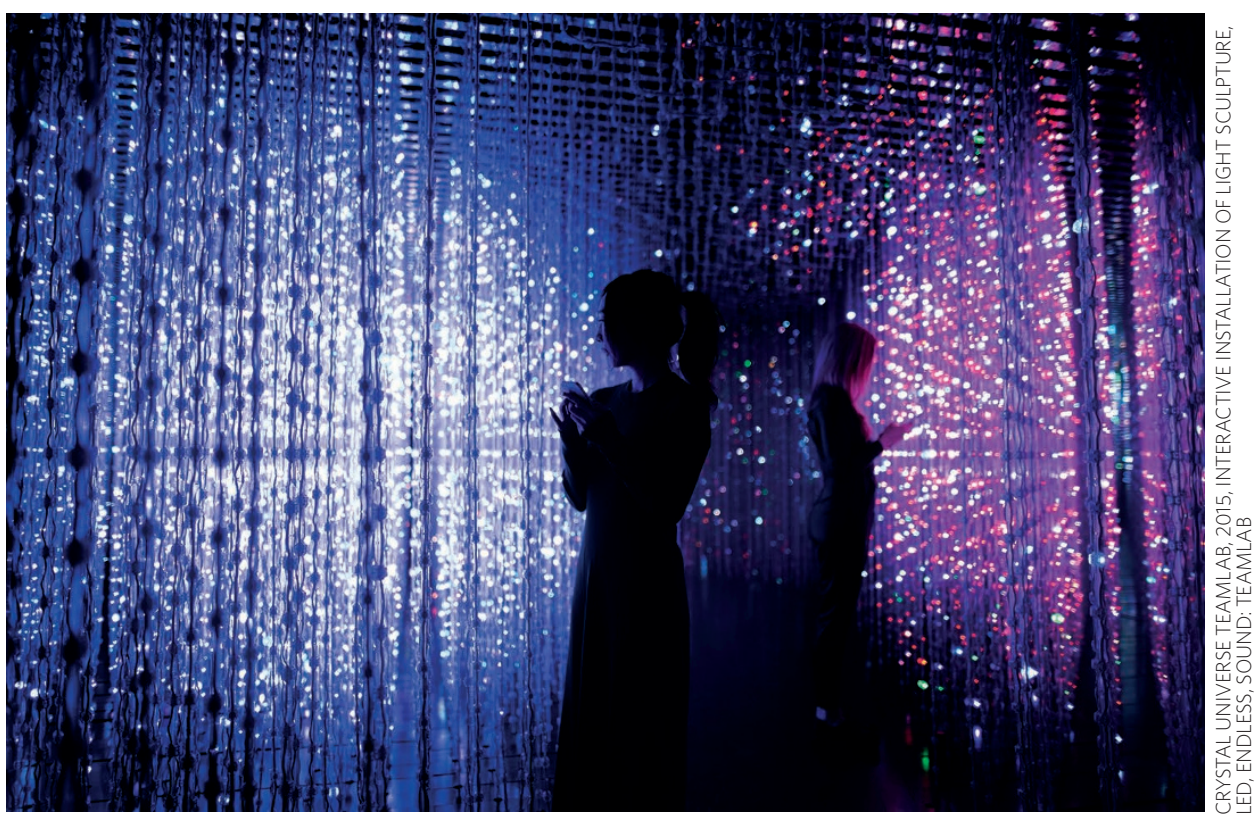

can move may seem a little far-fetched, but this is exactly what teamLab have created; in the so-called Sketch Aquarium, you can project your creative drawings onto a giant virtual aquarium. You'd think that the exhibition couldn't be any more immersive for children, but there is also the Sketch Town, which turns 2D drawings of cars and buildings into 3D objects that work together to make an interactive town.

Although the Sketch Aquarium and Sketch Town are fun, the interactions are a little limited, preventing anything like a story to form. There is one installation that can do this, however. The Story of the Time When Gods Were Still Everywhere is a giant screen filled with symbols that, when touched, evolve into the images they represent, such as birds, trees or elephants. The emerging objects then interact with their surroundings, which are influenced by other people - so your neighbour's wolf may try to eat your sheep.

There is one installation that focuses more on physics than on fun - sadly less popular with children. The Universe of Water Particles is a virtual waterfall that uses a computer to calculate the movement of hundreds of thousands of water particles, which flow in accordance with the laws of physics. The image is not of the particles, however, but of lines, which represent a selection of $0.1 \%$ of the particles, with the curvature of the lines dependent on the interaction of the particles. The choice of lines for the water is in the style of pre-modern Japanese paintings, and the waterfall is designed to lure people in, making them feel part of nature.

There are a number of other installations, but the exhibition has a grand finale: the Crystal Universe (pictured). Made from over 170,000 LEDs, the Crystal Universe uses lights to create an engrossing $4 \mathrm{D}$ environment that surrounds you. You can enter elements into the installation using a smartphone, but it is also influenced by the movement of every person inside the installation, meaning your experience is always unique.

\section{REVIEWED BY LUKE FLEET AND FEDERICO LEVI}

Future World opened on 12 March 2016 at the ArtScience Museum in Singapore. 